\title{
Cardiovascular function in elderly patients with chronic chagasic cardiopathy
}

\author{
Função cardiovascular em pacientes idosos \\ com cardiopatia chagásica crônica

\begin{abstract}
Manoel Otávio Costa Rocha ${ }^{1}$, Paulo César Correia ${ }^{1}$, Márcio Vinícius L. Barros ${ }^{1}$,
\end{abstract} \\ Rosália Moraes Torres ${ }^{1}$, Antônio Luiz P. Ribeiro' ${ }^{1}$ and Mauro Martins Teixeira²
}

\begin{abstract}
The objective of this work was to verify the degree and type of heart damage of elderly chagasic patients seen at an outpatient referral center and to compare them with the changes found in young chagasic patients with a similar degree of heart damage. Elderly and young patients without advanced cardiopathy presented good functional behavior. Elderly patients with advanced cardiopathy had more ventricular premature beats (VPB) in $24 \mathrm{~h}$ and less functional capacity in the exercise test than young patients of the same subgroup. There was a higher occurrence of effort-induced VPB and a lower prevalence of severe forms in elderly men, suggesting that Chagas'disease may have a worse evolution in males. The association of cardiac damage characteristic of aging with the secondary damage due to Chagas' disease could explain the greater functional damage found in elderly chagasic patients. Thus, it appears that the physiopathological components of Chagas'disease do have an influence on the clinical course of cardiopathy in the elderly population.
\end{abstract}

Key-words: Chagas'disease. Chagasic cardiomyopathy. Cardiovascular function. Elderly.

Resumo Este trabalho tem como objetivo verificar o grau e tipo de comprometimento orgânico-funcional cardíaco dos pacientes chagásicos idosos e compará-los com as alterações evidenciadas por chagásicos jovens com grau semelhante de dano miocárdico. Verificou-se que idosos sem cardiopatia avançada apresentaram bom comportamento funcional, semelhante ao dos jovens do mesmo estádio clínico. Idosos com formas avançadas apresentaram mais extra-sistolia ventricular ao Holter e menor capacidade funcional à ergometria que jovens do mesmo sub-grupo. Houve maior ocorrência de ESV esforço-induzida e menor prevalência de formas graves nos homens idosos, sugerindo evidências de pior evolução da doença de Chagas no sexo masculino. A associacão de alterações cardíacas próprias do envelhecimento ao dano secundário à doença de Chagas poderia explicar o maior comprometimento funcional encontrado em idosos. Assim, os componentes fisiopatológicos da doença de Chagas parecem influenciar a evolução da cardiopatia na população idosa.

Palavras-chaves: Doença de Chagas. Cardiomiopatia chagásica. Função cardiovascular. Idosos.

Chagas' disease is an important endemic disease in Brazil and it was estimated in 1985 that over 6 million people were infected in the Country ${ }^{24}$. Although acute cases of the disease have not been detected in the Country during the last few years due to effective control programs, there is much to be done for the many infected patients, a significant proportion of which will develop varying degree of cardiac disease. Moreover, it is doubtful whether specific treatment is really effective in the chronic phase of Chagas' disease.
In an endemic area, a chagasic patient usually becomes infected during childhood or as a young adult. Acute infection is, in most cases, oligosymptomatic and generally progresses to a clinically silent stage, denominated the indeterminate form ${ }^{21}$. The latter form may persist indefinitely or evolve into a clinically defined form after some 10 to 20 years ${ }^{7}$. The rate of conversion into clinically defined forms is considered to be around 2 to $5 \%$ a year ${ }^{7}$. Chronic chagasic cardiopathy is usually diagnosed in the third or fourth

\footnotetext{
1. Postgraduate Course of Tropical Medicine, Faculty of Medicine, Federal University of Minas Gerais. 2. Departament of Biochemistry and Immunology, Institute of Biological Science, Federal University of Minas Gerais, Belo Horizonte, MG, Brasil.

This work was supported by Conselho Nacional de Desenvolvimento Científico e Tecnológico (CNPq, Brazil)

Address to: Prof. Manoel Otávio da Costa Rocha. FM/UFMG. Av. Prof. Alfredo Balena 190, Santa Efigênia, 30130-100 Belo Horizonte, MG, Brasil.

Tel: 5531 3248-9822

e-mail: rochamoc@medicina.ufmg.br

Recebido para publicação em 15/8/2002

Aceito em 29/7/2003
} 
decade of life ${ }^{12}$. Once established, there is a tendency for patients to go on slowly and gradually to develop the various clinical presentations of Chagas' cardiopathy: conduction defects, arrhythmias, heart failure and thromboembolism ${ }^{16}$.

The presence of organic and functional damage to the heart constitutes a significant determinant of the capacity to work ${ }^{20}$. Moreover, functional and organic damage is a major determinant of early death, which frequently occurs during the most productive stages of life and before the patient has reached old age ${ }^{20}$. However, in as many as $40 \%$ of cases, chagasic patients with evidence of cardiac damage may develop a disease with a benign functional and evolutionary behavior that is compatible with a normal working life for many years.

The detection of chagasic infection in patients with advanced age is thought to reflect a benign character of the physiopathogenetic processes in the elderly ${ }^{1}$. Upon reaching the fourth decade of life, the chagasic patient without clinical manifestations of the disease would have little probability of presenting clinical forms of cardiopathy ${ }^{3}$. Similarly, Carneiro and Rezende ${ }^{5}$ believe that, in Chagas' disease, the unfavorable development manifests mainly before the age of 60 and that lifespan would not be noticeably affected in patients who reach the age of 50 without serious cardiopathy.

Aging determines histopathological changes in all of the structures of the heart, especially the myocardium ${ }^{19}$. In addition to these age-associated changes, there are also histopathological changes determined by cardiovascular pathologies common to the elderly patient, such as arterial hypertension, coronary and valvular pathologies. According to Carvalho Filho and colleagues ${ }^{6}$, in most elderly chagasic patients with heart failure, it appears that the changes associated with aging itself and with pathological processes common to the elderly are the main cause of the cardiopathy. The clinicalepidemiological characteristics, the degree of heart damage, the intensity of the functional disability and the tendency of the disease to evolve in chagasic patients who reach old age have not been completely established in the literature. The objective of this work was, thus, to verify the degree and type of heart damage of elderly chagasic patients seen at an outpatient referral center and to compare them with the changes found in young chagasic patients with a similar degree of heart damage.

\section{MATERIAL AND METHODS}

The present research was approved by the Ethics Committee of the Federal University of Minas Gerais (COEP/UFMG). Sixty seven chronic chagasic patients who were in regular treatment at the Chagas' Disease Outpatient Referral Center of the Hospital das Clínicas of the Federal University of Minas Gerais (HC/UFMG) from January 1998 to July 2000 were studied. Thirty four patients were elderly (age $>55$ years) and 33 young adults (age $<35$ years). The elderly patients were further divided into three subgroups, according to the findings in the electrocardiogram (ECG) and to the presence or not of cardiomegaly. These patients were paired with a similar number of young chagasic adults in the same clinical stage. All young chagasic patients were chosen randomly in a population regularly seen at the Outpatient Clinic. We regarded patients with Chagas' disease as those individuals whose serum tested positive for Trypanosoma cruzi by at least two of three different techniques (indirect immunofluorescence, indirect hemagglutination and enzyme-linked immunosorbent assay). All participants had to fill out a consent agreement to participate in the research and to complete all cardiac investigations proposed. Patients who had arterial hypertension (persistent blood pressure greater than $140 / 90 \mathrm{mmHg}$ ) clinical and/or laboratory evidence of chronic obstructive pulmonary disease, cardiomyopathy of non-chagasic etiology, valvular heart disease, ischemic heart disease, thyroid dysfunction, alcoholism, diabetes mellitus, water and electrolyte disturbances and chronic renal failure were excluded from the investigation. A basic laboratory blood evaluation consisting of the determination of the concentration of sodium, chloride, potassium, glucose, thyroid-stimulating hormone, free thyroxine, urea and creatinine was undertaken at Laboratorio Central of HC/UFMG.

Clinical staging and cardiocirculatory evaluation. Clinical staging was based on the intensity of the changes found in the 12-lead ECG and the presence or not of left ventricular dilatation, as determined by the measurement of the final diastolic diameter of the left ventricle (LVd). Included in subgroup I were patients with normal LVd and without significant electrocardiographic changes or with mild changes, such as left anterior fascicular block, low voltage in peripheral derivations, nonspecific changes of ventricular repolarization, sinus bradycardia. In subgroup II were individuals with normal LVd and with significant electrocardiographic changes considered to be indicative of heart damage of chagasic etiology (left bundle branch block, right bundle branch block associated with left anterior fascicular block, frequent and/or complex ventricular premature beats (VPB), subepicardiac ischemia, electric inactivity). In subgroup III were patients who showed echocardiographic signs of cardiomegaly (LVd $\geq 55 \mathrm{~mm}$ ).

A medical history and a standard clinical examination were undertaken in all recruited individuals. Patients were then divided according to the functional criteria of the New York Heart Association (NYHA). The following non-invasive cardiovascular investigations were carried out: a) twelve-lead resting ECG - always analyzed by the same observer and according to a classification system based on the 
Minnesota code adapted for Chagas' disease ${ }^{15}$; b) ergometric evaluation carried out according to the Bruce protocol on an ergometric treadmill (Digistress, Belo Horizonte, Brazil) and analyzed using computerized ergometric software (Heart Ware, Belo Horizonte, Brazil). The variables studied were the estimate of the maximum oxygen consumption $\left(\mathrm{VO}_{2} \max \right)$ and the incidence (appearance of arrhythmias not present in the resting state or increase in the number and/or complexity of the ectopic cardiac activity present at rest) and severity (presence of pairs, bigeminism, runs) of effort-induced VPB; c) dynamic 24-hour ambulatory electrocardiographic study - The recording was performed for a nominal period of 24 hours with the patient maintaining his/her routine activities on semiautomatic computerized system (DMI/Cardios Hospital system, São Paulo, Brazil). The variables studied were the quantity and complexity of VPB. Two or more consecutive VPB, multiform VPB and bigeminism were classified as complex exerciseinduced ventricular arrhythmias. d) Doppler echocardiogram - using unidimensional mode (M mode) and bidimensional mode in real time, colored, pulsed and continuous Doppler (Siemens, Germany). The variables studied were the final diastolic diameter of the left ventricle (LVd) and the ejection fraction (assessed by the methods of Teichholz and/or Simpson ).

Statistical analysis. Qualitative variables were analyzed using the chi-square test or the Fisher exact test, when necessary. Quantitative variables were submitted to Bartlett's test for homogeneity of variances. For variables with a normal distribution, analysis of variance (ANOVA) was used and data shown as mean \pm standard deviation. For variables with a non-normal distribution, Kruskal-Wallis non-parametric test was used for comparing median values. Differences were considered significant when $p$ values were smaller than 0.05 .

\section{RESULTS}

The clinical characteristics and distribution of elderly and young adult chagasic patients are shown in Tables 1 and 2. Fewer male patients were found in the group of elderly chagasic patients $(p=0.03)$ than in the young patients group. The distribution of patients according to their functional capacity, as assessed by the NYHA classification, shows that most patients were in class I or II; only one elderly chagasic patient was in class III and another in class IV (Table 1). The distribution of elderly and young chagasic patients was similar in regard to their clinical stage (Table 2).

A significantly greater incidence of effort-induced VPB was observed in elderly men than in elderly women $(p=$ 0.04). There was also a greater proportion of complex effort-induced VPB in elderly man, although this did not reach statistical significance $(p=0.08)$. There were no further differences between male or female elderly patients in the other variables studied and shown in Table 3.

In elderly and young chagasic patients classified as clinical stage I, there was no or little difference in parameters of clinical and cardiocirculatory functional behavior (Table 2). Elderly chagasic patients classified as clinical stage II presented a significantly greater number of VPB in the 24-hour ECG when compared to young adults $(p=0.04)$. Similarly, elderly patients classified as clinical stage II had a significantly lower functional capacity than young adults, as assessed by the $\mathrm{VO}_{2} \max (p=0.03)$. There were no differences between patients in this subgroup in regard to the incidence of complex VPB in the 24-hour ECG or in effort-driven VPB (Table 2). There were important differences between the elderly and young adult chagasic groups classified as clinical stage III. The number of elderly male patients was significantly lower than the number of young male patients $(p=0.03)$ and the $\mathrm{VO}_{2} \max$ was significantly lower in elderly patients $(p=0.001)$. Moreover, both the occurrence of single $(p=0.02)$ and of complex $(p=0.005)$ VPB in the 24-hour ECG were greater in elderly patients (Table 2). In this subgroup, there was no significant difference in the incidence of effort-induced VPB (Table 2).

\section{DISCUSSION}

The occurrence of premature deaths in chagasic patients with the severe forms of cardiopathy is a known phenomenon and can influence the study of elderly patients with Chagas' disease ${ }^{18}$. Due to a probable effect of natural selection, those individuals with less cardiac functional and organic damage and a better functional response to arrhythmogenic effort and stimuli are thought to survive longer and reach an advanced age. Following this line of thinking, Duarte and colleagues ${ }^{8}$ consider that the group of young adults (20-50 years old) is at a greater risk of presenting cardiopathy as a result of Chagas' disease. After the age of 50, the proportion of chagasic cardiopathy diminishes, probably due to the incidence of premature death.
Elderly chagasic patients are generally thought to present a relatively lesser degree of organic and functional Chagas-related cardiac damage and tend to die more of causes other than Chagas' disease ${ }^{131722}$. In this regard, it has been previously shown that the proportion of chagasic cardiopathy-associated death among chagasic patients is greater in the age group of young adults (20-50 years of age) and diminishes after the age of $50^{8}$. In a non-selected group of chagasic individuals followed for a period of 18 years, Kloetzel and Dias $^{10}$ also demonstrated a higher mortality in patients under the age of 50 than those between the age of 50-60 in the beginning of the observation period. According to Lopes and colleagues ${ }^{13}$ and Menezes 
Table 1- Clinical characteristics of the elderly and young adult chagasic patients.

\begin{tabular}{lrrr}
\hline Variable & Elderly & Young adults & P \\
\hline Number of patients & 34 & 33 & \\
Age (years \pm S.D.) & $60 \pm 4,5$ & $30 \pm 3.5$ & 0.00 \\
Males number (\%) & $15(44.1)$ & $24(72.7)$ & 0.03 \\
White number (\%) & $13(39.4)$ & $7(21.2)$ & 0.18 \\
Symptomatic number (\%) & $19(55.9)$ & $10(30.3)$ & 0.06 \\
NYHA ${ }^{1}$ Number (\%) & & & \\
I & $15(44.1)$ & $23(69.7)$ & \\
II & $17(50.0)$ & $10(30.3)$ & \\
III & $1(2.9)$ & - & \\
IV & $1(2.9)$ & - & \\
\hline INYHA Function & & &
\end{tabular}

${ }^{1}$ NYHA: Functional classification of the New York Heart Association.

Table 2 - Distribution of elderly and young adult chagasic patients according the clinical sub-groups and cardiovascular functional parameters.

\begin{tabular}{|c|c|c|c|c|c|c|c|c|c|}
\hline \multirow[b]{2}{*}{ Variables } & \multicolumn{3}{|c|}{ Sub-group I } & \multicolumn{3}{|c|}{ Sub-group II } & \multicolumn{3}{|c|}{ Sub-group III } \\
\hline & elderly & young & $\mathrm{P}$ & elderly & young & $\mathrm{P}$ & elderly & young & $\mathrm{P}$ \\
\hline Number of patients & 8 & 10 & & 12 & 10 & & 14 & 13 & \\
\hline Ejection fraction (\%) & 64.0 & 62.5 & 0.50 & 61.0 & 60.0 & 0.53 & 44.0 & 50.0 & 0.06 \\
\hline Estimated $\mathrm{VO}_{2} \max (\mathrm{ml} / \mathrm{kg} / \mathrm{min})$ & 38.0 & 42.0 & 0.38 & 36.5 & 56.0 & 0.03 & 32.5 & 50.0 & 0.001 \\
\hline Number of VPB in $24 \mathrm{~h}$ & 4.5 & 3.0 & 0.65 & 1034.5 & 35.0 & 0.04 & 2959.0 & 459.0 & 0.02 \\
\hline VPB in $24 \mathrm{~h} /$ total patients & $2 / 8$ & $1 / 10$ & 0.55 & $8 / 12$ & $4 / 10$ & 0.39 & $14 / 14$ & $7 / 13$ & 0.005 \\
\hline \multicolumn{10}{|l|}{ Number of patients with VPB in } \\
\hline the ET/total patients & $2 / 5$ & $2 / 10$ & 0.56 & $6 / 12$ & $5 / 10$ & 1.0 & $6 / 8$ & $10 / 12$ & 1.0 \\
\hline \multicolumn{10}{|l|}{ Number of patients with complex } \\
\hline VPB in the ET/total patients & $1 / 5$ & $0 / 10$ & 0.33 & $5 / 12$ & $1 / 10$ & 0.16 & $5 / 8$ & $5 / 12$ & 0.32 \\
\hline
\end{tabular}

The number of ventricular premature beats (VPB) and frequency of complex VPB in 24 h were evaluated by dynamic 24-hour ambulatory electrocardiography. Ejection fraction was estimated by Doppler echocardiography and ergometric evaluation (ET) estimated maximum oxygen consumption $\left(\mathrm{VO}_{2} \mathrm{max}\right)$ and the incidence and severity of effort-induced VPB.

Table 3 - Clinical and functional characteristics of elderly patients according to sex.

\begin{tabular}{lccr}
\hline Variables & Female & Male & P \\
\hline Sub-group I (n) & 3 & 5 & \\
Sub-group II (n) & 9 & 3 & \\
Sub-group III (n) & 7 & 7 & \\
Age (years \pm S.D.) & $59 \pm 4$ & $61 \pm 5$ & 0.5 \\
Number of VPB in 24 h & 1031 & 1684 & 0.17 \\
Number of patients with complex VPB & & & \\
$\quad$ in 24 h/total patients & $12 / 19$ & $12 / 15$ & 0.45 \\
Ejection fraction (\%) & 60 & 51 & 0.17 \\
LVd (mm) & 50 & 53 & 0.22 \\
Estimated VO ${ }_{2}$ max (ml/kg/min) & 35.0 & 39.5 & 0.09 \\
Number of patients with VPB $\quad$ & & \\
$\quad$ in the ET/total patients ${ }^{(1)}$ & & $7 / 8$ & 0.042 \\
Number of patients with complex VBP & $7 / 17$ & & \\
$\quad$ in the ET/total patients ${ }^{(1)}$ & & $6 / 8$ & 0.08 \\
\hline
\end{tabular}

The number of ventricular premature beats (VPB) and frequency of complex VPB in $24 \mathrm{~h}$ were evaluated by dynamic 24-hour ambulatory electrocardiography. Ejection fraction and diameter of the left ventricle during diastole (LVd) was estimated by Doppler echocardiography and ergometric evaluation (ET) estimated maximum oxygen consumption $\left(\mathrm{VO}_{2} \max \right)$ and the incidence and severity of effort-induced VPB. (1) Two female and seven male chagasic patients did not undergo the treadmill test. 
and colleagues ${ }^{17}$, chagasic individuals frequently die of causes other than due to trypanosomiasis after the age of 50 . The latter study was based on clinical and necroscopic data and suggested that the lesser incidence of death for chagasic reasons in elderly patients was associated with a lesser degree of cardiac damage, especially of the myocardium and of the excitatory and conduction system. The incidence of sudden death was observed in nearly $50 \%$ of the non-elderly chagasic patients studied in autopsies, whereas none of the elderly chagasic individuals died suddenly ${ }^{17}$.

In the present study, when elderly and young adult chagasic patients were compared in each clinical stage, it was observed that elderly chagasic patients without advanced cardiopathy presented good functional behavior, similar to that of young adults. As the degree of cardiac damage worsened, elderly chagasic patients presented more functional changes than young adults. In this regard, elderly patients with advanced forms of cardiac damage had more VPB in the 24-hour ECG and a lower functional capacity than young adults (Table 2). Both elderly and young patients with advanced cardiopathy had effortinduced VPB and no differences were observed between the groups (Table 2). The cardiac functional capacity is knowingly lower in elderly patients than in young adults ${ }^{4}$. Moreover, frequent and complex VPB in the 24-hour ECG may be found in the healthy geriatric population ${ }^{9}$. So, age per se may account for the presence of frequent and complex VPB in the 24-hour ECG ${ }^{11}$. Nevertheless, it appears that the association of age and this ventricular arrhythmia is more evident in chagasic patients than in the normal population ${ }^{23}$. Thus, it appears that the physiopathological components of Chagas' disease do influence the evolution of the cardiopathy in the elderly population.

The combination of age- and Chagas' diseaseassociated cardiac damage may explain the observation that elderly patients present more VPB in 24 hours than young adults. However, there was a similar incidence of effort-induced VPB in elderly and young adult chagasic patients in all clinical stages. The latter observation could be interpreted in, at least, two ways. The presence of effort-induced VPB in elderly chagasic patients may occur in a more favorable physiopathological circumstance than in young patients, thus, allowing longer survival. Alternatively, effort-induced VPB may have appeared at a later stage in life in the elderly patients studied here, allowing them to survive for longer.

Several authors suggest that male chagasic patients tend to have a worse clinical development ${ }^{21423}$. In our sample, there was a higher incidence of effort-induced VPB in elderly men than in elderly women, suggesting the existence of a greater functional damage in the former population. The lower prevalence of severe clinical forms of Chagas' disease among elderly men observed here may be explained by a process of natural selection. In this scenario, male patients who tend to have a more severe disease than female patients would die more frequently and earlier and, thus, not be available for evaluation at an advanced age $\mathrm{e}^{1423}$.

The study of the clinical development of these patients may contribute to a better understanding of the natural history of Chagas' disease and help in the definition of markers of prognosis.

\section{REFERENCES}

1. Almeida Neto JC, Valle de Mello J, Barbosa W. Doença de Chagas, correlação sorológica em grupo de indivíduos idosos. Revista da Sociedade Brasileira de Medicina Tropical 4:75-81, 1970.

2. Barreto ACP, Arteaga E, Mady C, lanni BM Bellotti G, Pileggi F. Sexo masculino. Fator prognóstico da doença de Chagas. Arquivos Brasileiros de Cardiologia 60:225-228, 1993.

3. Brasil A. Evolução e prognóstico da doença de Chagas. Arquivos Brasileiros de Cardiologia 18:365-380, 1965.

4. Bruce RA, Hornster TR. Exercise stress testing in evaluation of patients with ischemic heart disease. Progress in Cardiovascular Disease 11:371- 390, 1969.

5. Carneiro O, Rezende JM. Doença de Chagas e longevidade. Arquivos Brasileiros de Cardiologia 38:381-384, 1982.

6. Carvalho Filho ET, Figueira JL, Pasini U, Forti NA, Curiati JAE, Ferreira MLM, Serro Azul LG. Aspectos da doença de Chagas no idoso. Arquivos Brasileiros de Cardiologia 45:102-107, 1985.

7. Dias JCP. The indeterminate form of human chronic Chagas' disease. A clinical epidemiological review. Revista da Sociedade Brasileira de Medicina Tropical 22:147-156, 1989.

8. Duarte GC, Haddad N, Fávero M. Análise do componente etiológico exclusivamente chagásico no estudo da prevalência de cardiopatias. Revista do Instituto de Medicina Tropical de São Paulo 9:327-332, 1967.

9. Fleg JL, Kennedy HL. Cardiac arrhythmias in a healthy elderly population. Chest 81:302 -307, 1982.

10. Kloetzel K, Dias JCP. Mortality in Chagas' disease: life table for the period 1949-1967 in an unselected population. Revista do Instituto de Medicina Tropical de São Paulo 10:5-8, 1968.

11. Kostis JB, McCrone K, Moreyra AE, Gotzoyannis S, Aglitz NM, Natarajan N, Kuo PT. Premature ventricular complexes in the absence of identifiable heart disease. Circulation 63:1351-1356, 1981.

12. Laranja FS, Dias E, Nobrega G, Miranda A. Chagas' disease: a clinical epidemiologic, and pathologic study. Circulation 14:10351059, 1956.

13. Lopes ER, Moraes CA, Chapadeiro E, Mineo JR, Leite LC, Guimarães AHB, Rocha A, Gava M. Prevalência da infecção chagásica em necropsias no Triângulo Mineiro. Revista do Instituto de Medicina Tropical de São Paulo 26:125-129, 1984.

14. Macedo VO. Influência da exposição à reinfecção na evolução da doença de Chagas. (Estudo longitudinal de cinco anos). Revista de Patologia Tropical 5:33-116, 1976. 
15. Maguire JH, Mott KE, Souza JAA, Almeida EC, Ramos NB, Guimarães AC. Electrocardiographic classification and abbreviated lead system for population-based studies of Chagas' disease. Bulletin of the Pan American Health Organization 16:47-58, 1982.

16. Marin Neto JÁ, Simões MV, Sarabanda AVL. Chagas' heart disease. Arquivos Brasileiros de Cardiologia 72:264-280, 1999.

17. Menezes M, Rocha A, Silva AC, Silva AM. Causas básicas de morte em chagásicos idosos. Arquivos Brasileiros de Cardiologia 52:75-78, 1989.

18. Mota EA, Guimarães AC, Santana OO, Sherlock I, Hoff R, Weller $\mathrm{H}$. A nine-year prospective study of Chagas' disease in a defined rural population in Northeast Brazil. American Journal of Tropical Medicine and Hygiene 42:429-440, 1990.

19. Pomerance A. Cardiac pathology in the aged. Geriatrics 23:101114, 1968.

20. Porto CC, Rassi A, Faria GHDC. Aspectos Sócio-Econômicos e Médicos-Trabalhistas In: Cançado JR, Chuster M (eds)
Cardiopatia Chagásica, Imprensa Oficial, Belo Horizonte, p. 362-366, 1985.

21. Ribeiro ALP, Rocha MOC. Forma Indeterminada da doença de Chagas: considerações acerca do diagnóstico e do prognóstico. Revista da Sociedade Brasileira de Medicina Tropical 31:301314, 1998.

22. Silva AC. Doença de Chagas no paciente idoso. Revista da Sociedade Brasileira de Medicina Tropical 25(supl III): 69, 1992.

23. Zicker F, Smith PG, Almeida Netto JCA, Oliveira RM, Zicker SEM. Physical activity, opportunity for reinfection, and sibling history of heart disease as risk factors for Chagas' cardiopathy. American Journal of Tropical Medicine and Hygiene 43:498505, 1990.

24. World Health Organization. Expert Committee on the Control of Chagas Disease. Control of Chagas disease. World Health Organization technical report series, 905, Geneva, 2002. 